\title{
Markerless Augmented Reality Utilizing Gyroscope to Demonstrate the Position of Dewata Nawa Sanga
}

\author{
https://doi.org/10.3991/ijim.v12i1.7527 \\ I Wayan Andis Indrawan( $\left.{ }^{\bowtie}\right)$, I Putu Agung Bayupati, Desy Purnami Singgih Putri \\ Udayana University, Bali, Indonesia \\ andisindrawan@gmail.com
}

\begin{abstract}
Dewata Nawa Sanga in Hinduism has an important role as the foundation of the religious concept implemented by Hindus in Bali, Indonesia. It has the meaning of nine deities or manifestations of Ida Sang Hyang Widhi Wasa (God Almighty) that guard or control the nine wind direction. Dewata Nawa Sanga in terms of education in Bali has been learned by the elementary school students. However, in social life the concept of Dewata Nawa Sanga itself has not been attached and understood by all Balinese Hinduism yet. Based on the problem in social life, there is an idea to develop Markerless Augmented Reality Utilizing Gyroscope to Demonstrate the Position of Dewata Nawa San$g a$. This application is designed to know, recognize, and understand the characteristics of Dewata Nawa Sanga using gyroscope. This sensor serves to fulfill the object of the deities in the coordinates to be determined. Furthermore, it serves to provide information about Dewata Nawa Sanga along with the innovative and informative $3 \mathrm{D}$ animation. The result of usefulness questionnaire of this application percentage value average is $88.4 \%$. It can be concluded that $\mathrm{AR}$ Dewata Nawa Sanga is very useful and helpful for learners in exploring the Dewata Nawa Sanga position in a real-world environment. The result of usability and satisfaction questionnaire of this application percentage value average is $84.8 \%$. It shows that the application is very useful for the participants to learn Dewata Nawa Sanga and very satisfied to use.
\end{abstract}

Keywords-Augmented Reality, Gyroscope, Dewata Nawa Sanga, 3D Object.

\section{Introduction}

A technology that can combine two dimensions with three-dimensional virtual objects into the three dimension zone and showed in real time simultaneously called Augmented Reality. This technology is more useful as a tool in order to help develop the interaction and perception of users with reality. Unity tool development ecosystem is a rendering engine for creating the attractive and interactive three-dimensional content and two-dimensional content [1]. In this paper, the application is presented to explain the utilization of Augmented Reality using gyroscope sensor and is organized as: section2: Related Work, section3: Augmented Reality In Cultural Education, sec- 
tion4: Research Methodology, section5: Implementation of System, section6: Experiments Design, section7: Experiments Result and section8: Conclusion.

\section{Related Work}

The previous research used marker based Augmented Reality in developing the education of balinese culture application [2][3]. One of them is a study that explains the balinese culture application of Augmented Reality technology used to promote tourism object in Tanah Lot Temple, Bali Island, Indonesia. DewataAR application uses brochure as a Marker to display Augmented Reality in the form of a video, 3 dimensional objects, and audio which is the advantages of this research. However, this study has the only shortcomings of using brochures as a Marker that is easily to lose if the user is careless [4]. In Augmented Reality technology, the concept of introducing image, object recognition and $3 \mathrm{D}$ object tracking is not a new concept and has been used generally by markers in visual form. This visual marker has been widely used in some Augmented Reality applications in several studies. In order to implement the performance of the Augmented Reality system, some of these applications usually depend on the tracking method using marker detection, pose estimation, etc. based on the application. However, the use of this marker may result in limited interactivity restricted to a wide range of images and objects realized in the form of borders and barcodes to create markers. Therefore, in order to realize this approach, this marker mark must be printed and stored for future use of this application. Unlike Augmented reality technology that uses marker bases, in a markerless based augmented reality system any part of the environment can actually be used as a target or marker; therefore, each coordinate position can be traced to place virtual objects in both $2 \mathrm{D}$ and $3 \mathrm{D}$ form [5]. Based on that assumption, markerless augmented reality is an interesting technology to develop. Markerless Augmented has many types among others, combination with GPS, motion, face tracking and the balance of orientation with gyroscope sensor. Gyroscope is a tool to measure orientation based on the working principle of angular momentum. It is widely used to measure angular velocities, how fast something rotates around an axis. Furthermore, most smartphones nowadays have this tool installed [6]. This study aims to develop the utilization of gyroscope sensors in order to create augmented reality-based educational applications. The topic is chosen in order to realize that this research is a religious theory of Hindu about the constellation of nine deities that holding the cardinal directions called Dewata Nawa Sanga [7]. Dewata Nawa Sanga means nine deities or the manifestations of Ida Sang Hyang Widhi Wasa (God Almighty) that guard or control the nine wind direction. The nine deity such as Vishnu that guard the north wind direction, beside the Vishnu there is Sangkara that preserve the north west wind direction, Mahadev is a deity that guard the west wind direction, beside Mahadev there is Isvara that preserve the east wind direction, then Rudra that guard the south west wind direction, the next is a deity called Sambhu that preserve the north east wind direction, Brahma that guard the south wind direction, the next is a deity called Mahesora that preserve the south east wind direction, and the last is Shiva that guard the middle wind direction. The nine 
deity has their own sakti (wife), senjata (weapon), wahana (rides) and another information. This topic is chosen because balinese hinduism tends to hardly memorize names of deities, sakti (deities wife) senjata (deities weapon), wahana (deities rides) dan other information of the deities. The goal of this research is establishing an application that can run in Android mobile devices and can provide information and visualization and the position of Dewata Nawa Sanga in 3D using gyroscope sensors. The gyroscope sensor plays an important role in this application. This sensor serves to fulfill the object of the deities in the coordinates to be determined. Gyroscope sensors used to create augmented reality cameras that becoming the main axis for positioning the nine deities in each wind direction that will appear without markers to display or usually called markerless.

\section{$3 \quad$ Augmented Reality In Cultural Education}

Augmented Reality enables combining digital content into our view of the real world using smartphone cameras and tablet devices. Some examples of the types of content that can overlay on our perception of the real world include images, 2 Dimension and 3 Dimension, web, video, text and audio. Geolocation or image recognition can associate this content with real-world elements. This technology has great potential to use as well as being involved in many types of fields to improve the applicationuser insight into the world. Learning about cultural heritage is one of the many fields that can be more profitable if it is applied using this technology [8]. Augmented Reality in relation to the educational context in order to support cultural heritage learning for students and public will be discussed further in this paper.

Augmented Reality has many functions and can demonstrate temporal and spatial concepts as well as contextual relationships between real objects and virtual objects. Virtual objects are easy to animate; they can respond to user actions, they are not limited by time, they are not expensive, they are practical to use. These are the main advantages of using Augmented Reality and the main factors that make Augmented Reality becoming a powerful culture educational tool [9]. As an example, Augmented Reality Book and Stick Application about Pandawa Puppet Shadow Details, accompanied by Pandawa Puppet Shadow information, video application and also narration of each character from Pandawa Puppet Shadow was installed on Android smartphones. Pandawa Puppet Shadow characters are more interesting and interactive. This application can make users motivated to play shadow puppet and interested to learn and explore this topic [10]. Another study of cultural education is Virtual Hagia Sophia. Under the Acoustic Heritage Conservation by the Rise and Identification of the Sinan's Mosque project. The previous Hagia Sophia Museum is a mosque known as the Sinan's Mosque. The goal of the project is to develop an interactive simulation of the Hagia Sophia museum that produces a realistic environment with illuminations. The project also features character simulation and sound background [11]. Another research is the Augmented Reality Book application for introducing the Balinese gamelan (musical instrument). This application uses library vuforia that can play a voice and display $3 \mathrm{D}$ objects Balinese gamelan in a real world using books, 
smartphones and tablets. The final result of this research is a book contains markers that related to Balinese gamelan functioned as a marker. Augmented Reality Book Android-based application is capable of displaying objects gamelan gong kebyar (musical instrument) in 3D form and voice will be heard if one of the gamelan pictures in marker is pressed. Besides, it displays voice narration as an explanation of this application. This application can be used as a medium to introduce and preserve the national culture [3].

\section{$4 \quad$ Research Methodology}

This section describes the description of system, Schematic of System Development, and general description of AR Dewata Nawa Sanga Application that has been developed. Research methodology is a sequence of steps used as a reference in conducting research.

\subsection{Schematic of System Development}

The Schematic of System Development is divided into two important parts which are back-end and front-end parts, each of which describes the process flow of the system that has been developed. The first process on the back-end includes the creation of Augmented Reality application with the engine used is Unity with a camera called CamGyroAR.cs and gyroscope features available on the smartphone. The creation of 3-dimensional and animated models uses Autodesk Maya software where the results obtained from the manufacture of 3-dimensional model and animation exported into the form of fbx file. The second process of the back-end part is to merge CamGyroAR.cs (tracking gyroscope) with 3-dimensional model. The proposed merger is the interrelated relationship between tracking gyroscope and 3-dimensional model. The final step of the back-end part is the establishment of the Application Package File (APK file). APK files are established to enable applications that have been created to be used directly on Android smartphones.

The process on the front-end is when the APK file has been installed on an Android smartphone or tablet. The main process on the front-end is to do tracking using gyroscope sensor to display 3-dimensional objects of Dewata Nawa Sanga, Nawa Sanga animation and Dewata Nawa Sanga information. Gyroscope tracking works with a 360-degree rotation technique in which each rotation has a different output according to the gravity performed by the user of the system. The Schematic of System Development can be seen in the figure (Fig 1). 


\section{BACK-END}

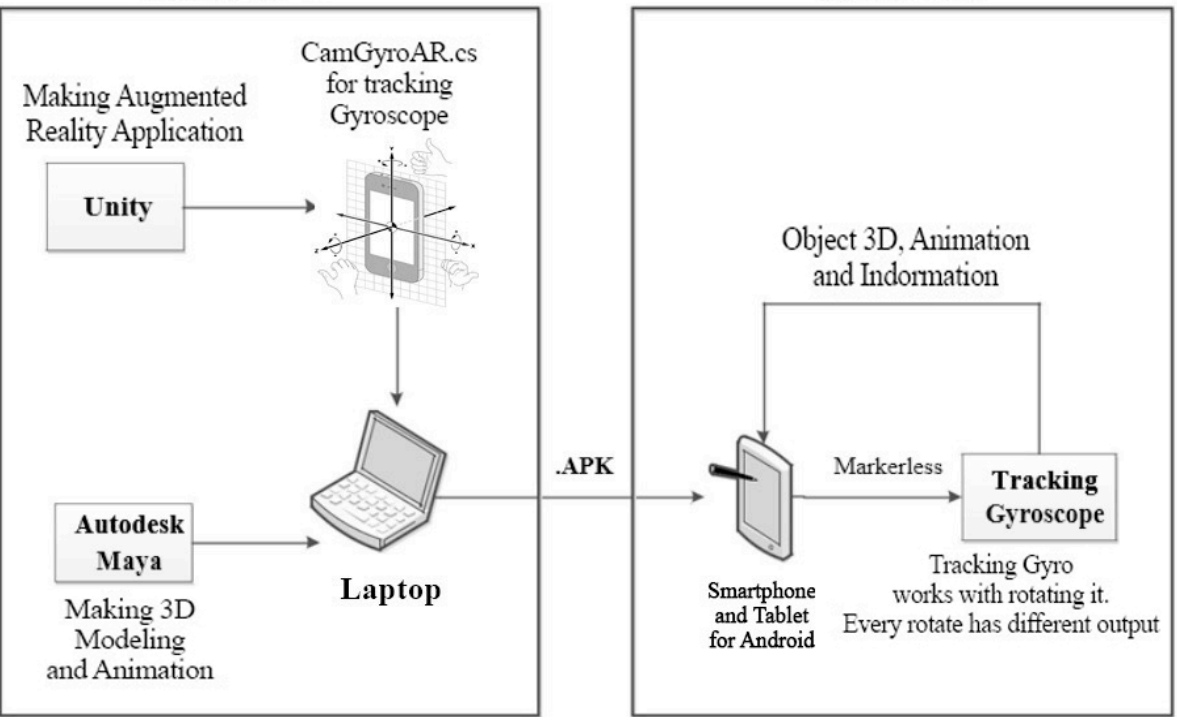

Fig. 1. Schematic of System Development

\subsection{User Experience Flowchart}

In general, the application of Augmented Reality Dewata Nawa Sanga is started from the initial appearance of Home Screen. Home Screen has 4 buttons, AR Dewata Nawa Sanga, tutorial, about and exit. AR Dewata Nawa Sanga button is the main process in Augmented Reality Dewata Nawa Sanga application where user directs smartphone camera to track gyroscope by rotating to identify $3 \mathrm{D}$ object. Positions are tracked by the camera according to the position of objects that have been assigned to Unity 3D, which displays 3-dimensional objects, animations and information when the target position is tracked. Application Augmented Reality Dewata Nawa Sanga also has another button that is a tutorial. It serves to display the use of this application and button about which contains information from this application developer. The user experience flowchart can be seen in the following figure (Fig 2). 
Paper-Markerless Augmented Reality Utilizing Gyroscope to Demonstrate the Position of Dewata Nawa..

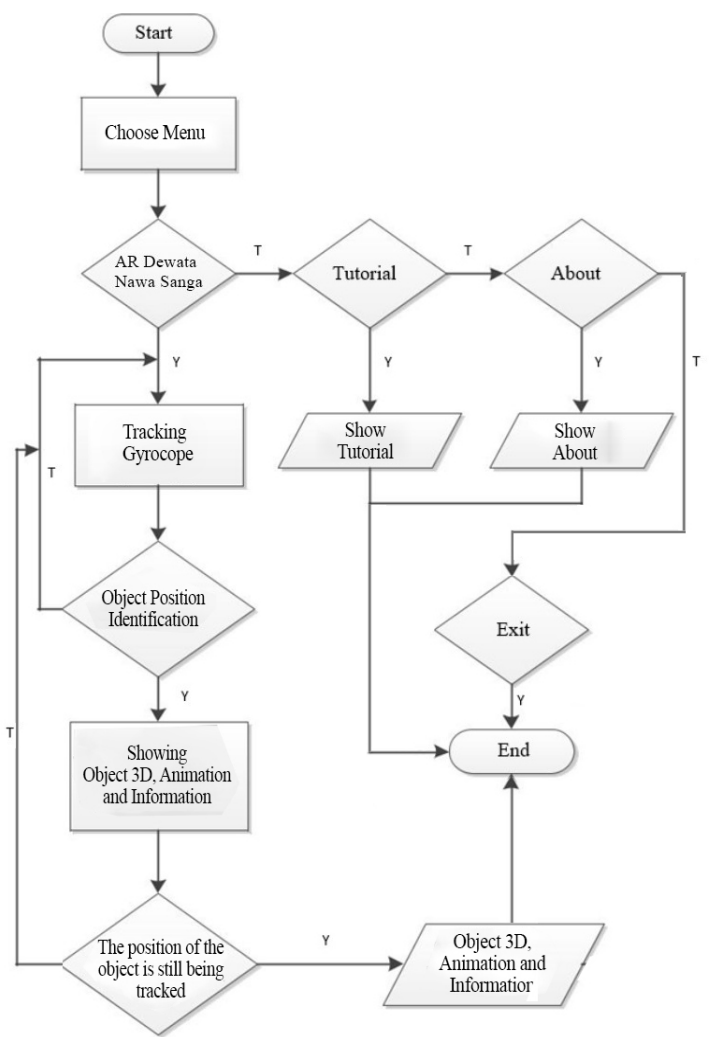

Fig. 2. User Experience Flowchart

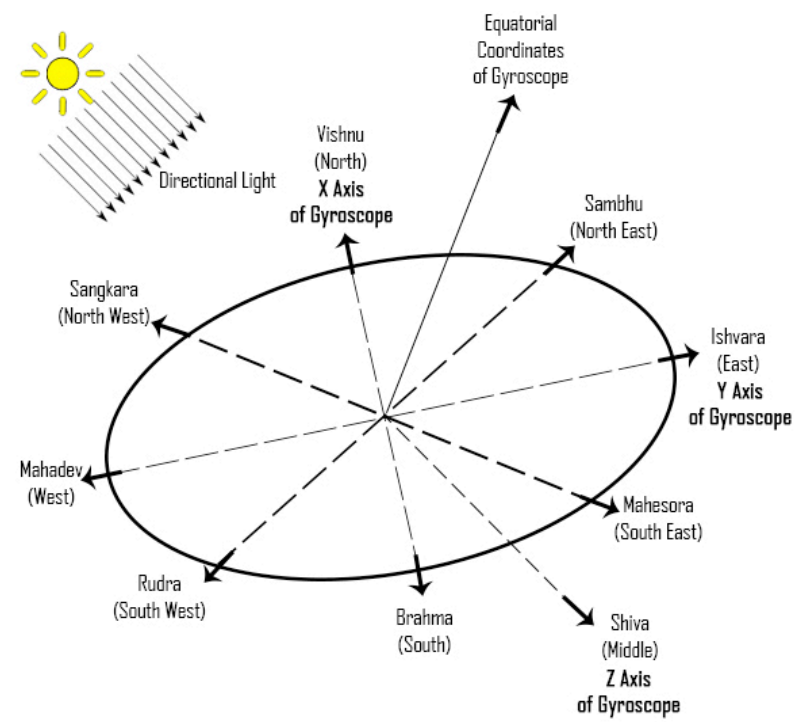

Fig. 3. Dewata Nawa Sanga simulation model 


\subsection{AR View Function}

AR Dewata Nawa Sanga application shows the virtual objects of the nine deities in each wind direction onto a real world using smartphone camera as a background to realize the virtual objects of deities appearing to the reality environment. To make the right coordinate of the wind direction in AR view, an accurate compass sensor is required from the smartphone or tablets through the built-in sensors. Therefore, this compass is combined with the gyroscope to make an exact coordinate. This gyroscope sensor becomes an important role in view AR View scene. It is because AR Camera will only work if the camera from the smartphone has a gyroscope sensor. This gyroscope sensor that makes the camera from the smartphone can be rotated 360 degrees. In addition, the function of the gyroscope is to act as a coordinate to place the object of Dewata Nawa Sanga. The existence of gyroscope sensor in the smartphone will make this application won't run well even be crashed because it can not realize the commands in the program code.

As in the simulation model that contained in figure (Fig 3) describes the AR display area loaded in the gyroscope scheme. The screen angle is divided into three parts such as $\mathrm{x}$-axis, $\mathrm{y}$-axis and z-axis. The center of the gyroscope is at the coordinate point of $0,0,0$ which becomes the Equatorial Coordinates of the gyroscope. Based on the point of the axis, it can be determined the coordinates of each deity. In the north of the wind direction there is a deity that called Vishnu, in the north-east there is a deity that called Sambhu, east wind direction from the middle there is a deity that called Isvara, a deity that called Mahesora is in the south-east, a deity that called Brahma is in south from the middle of the gyroscope, a deity that called Rudra is in the southwest, a deity that called Mahadev is in the west, a deity that called Sangkara is in the north-west, and the last is a deity that called Shiva. The deity that called Shiva must be placed in the middle position that is on $x$-axis and $y$-axis at the point 0 , as well as $\mathrm{z}$-axis is at the point -10 . Therefore, it can be seen in the AR view by steering the smartphone downwards. This AR view implementation uses a reality camera background loaded in a plane. To add a unified impression of 3D virtual object to the real world, it is combined by adding directional light effects. Therefore, 3D objects of deities have their own shadows derived from directional lights that act as the sun from this AR view.

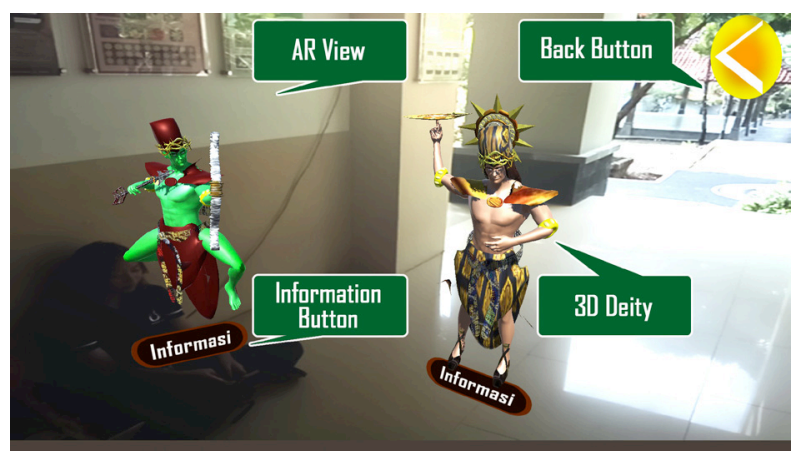

Fig. 4. AR view interface 
Complete AR view interface from AR Dewata Nawa Sanga is shown in figure (Fig 4). AR view loaded with reality camera as background made with plane. Furthermore, deities are loaded in $3 \mathrm{D}$ objects made as closely as possible from various sources. So it can be visualized with good quality and attractive. The deities are given an animation effect, therefore, it looks more interesting. During development, initially in AR View contains very many objects such as objects of deities, object of Wahana's (deities ride), objects of Sakti's (deities wife), object of Senjata's (deities weapon) and detail information of menu and animation of all objects are in one scene. In the trial of this scene, the application runs quite smoothly through unity remote. However, when in the build and run on a smartphone with RAM capacity under $2 \mathrm{~GB}$, this application runs very slowly. In order to solve this problem, this application should be created with AR View and minimalist mode and not to load a lot of objects. One scene only displays object of deities and information buttons in AR View. Button information will be a trigger to the Information View which serves to be an additional scene to display the details of each deity. AR View does not accommodate a lot of objects; therefore, they are moved to Information View scene. This is as the solution of the slow AR camera scene that previously loaded many objects in one scene.

In order to get the detail deities information and to know the relevance of deity with other Hindu religion concepts, it should be provided one button in every deity. The button is called the information button. This Button is made with the world space canvas so it can be placed just below of each deity. In order to switch from AR view to the main menu, there is a button back in the upper right corner of the AR view scene. Therefore, the user who wants to go back to the main menu and switch to another menu can be realized. Directional lights make deities look to match the reality of the camera background.

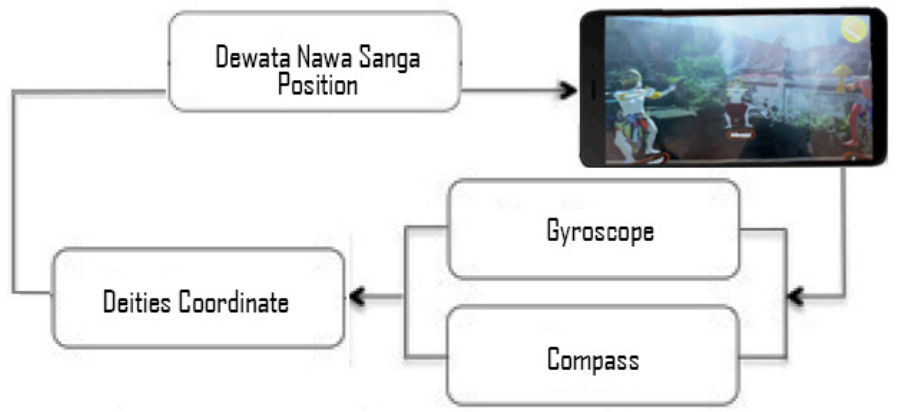

Fig. 5. Procedure for observing deities position in AR view

The procedure for observing deities position in AR view can be seen in figure (Fig 5 ). In the scheme, smartphone needs sensors contained in it. These sensors include gyroscope sensors and compass sensors. The gyroscope sensor serves to be an area of the AR view to place the nine deities in the direction of the wind with the center point in the equatorial coordinates of gyroscope. If the smartphone of the user does not have a gyroscope sensor, AR view won't work. The next sensor is a compass sensor. This sensor also has a big contribution that helps the gyroscope sensor to determine the 
direction of the actual and factual winds. If the smartphone of the user does not have this sensor, the direction of the indicated wind can be chaotic and not in accordance with reality. After the gyroscope and compass sensor are collaborated to determine the points to be the ninth coordinates of the deities, the deities coordinate is obtained. Deities coordinate is the reference of the ninth point of Dewata Nawa Sanga position. The position of the nine deitis will be displayed in the AR view menu. This application is a simple application that utilizes built-in sensors from existing smartphones with a growing augmented reality technology.

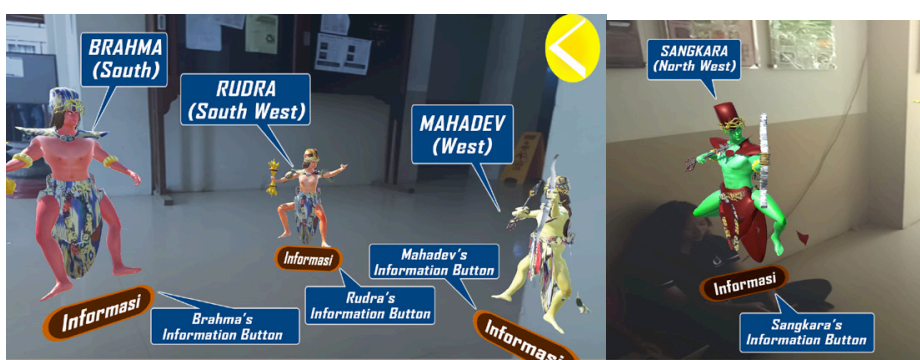

(a)

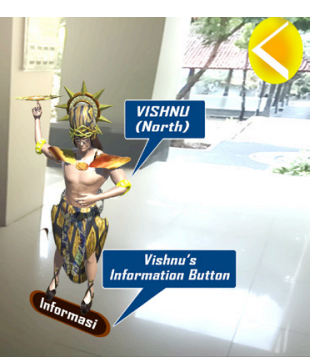

(b)

Fig. 6. AR view

Before entering the AR view, the user will be in intro scene loading screen and the main menu display. The views of the three scenes are interesting to attract users in using this application further.

In AR view there are nine object deities in augmented reality mode. The augmented reality does not require markers to trigger objects to perform, but instead utilizes gyroscope and compass sensors. The nine deities appear in the AR view located in every corner of the wind. In the north of the pivot point, there is the Wisnu, in the north-east there is Sambhu, in the east of the pivot point there is the Iswara, Mahesora in the south-east, Brahma is south of the pivot point of the gyroscope, Rudra in the south-west (a) that showed in figure (Fig 6), Mahadev in the west, Sangkara in the north-west, and the last deity is Siwa. This last deity must be placed in the middle position that is on $\mathrm{x}$-axis and $\mathrm{y}$-axis in the point 0 , as well as $\mathrm{z}$-axis is at the point -10 . Therefore, it can be seen in the AR view by steering the smartphone downwards.

In order to get the detail deities information and to know the relevance of deity with other Hindu religion concepts, it should be provided one button in every deity. The button is called the information button (b) that showed in figure (Fig 6). This Button is made with the world space canvas so it can be placed just below of each deity. In order to switch from AR view to the main menu, there is a button back in the upper right corner of the AR view scene. Therefore, the user who wants to go back to the main menu and switch to another menu can be realized. 


\subsection{Information View Function}

Information View Function is presented in each scene for every deity. Therefore, each deity has His own scene to explain the information of the deities overall and can be related to the other Hindu religious concepts. Display interface of the scene Information View Function is actually very simple; however, it contains much useful information for users.

In order to go to the Information page, the user first goes through the loading screen (a) that shown in figure (Fig 7). The function of this loading screen is to provide a transition from the AR View and Information View scenes that load many heavy objects. Therefore, the loading screen will give a fast time to load each scene. It will give the impression of this lightweight application and not make the smartphone takes up a lot of RAMs.

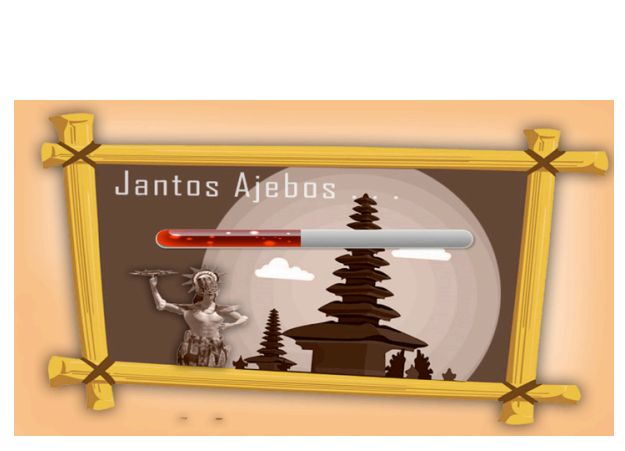

(a)

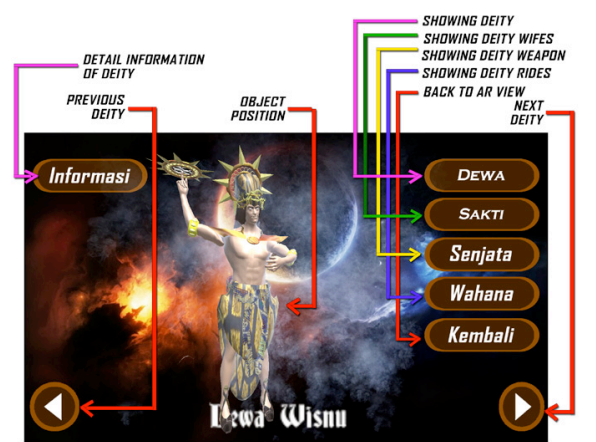

(b)

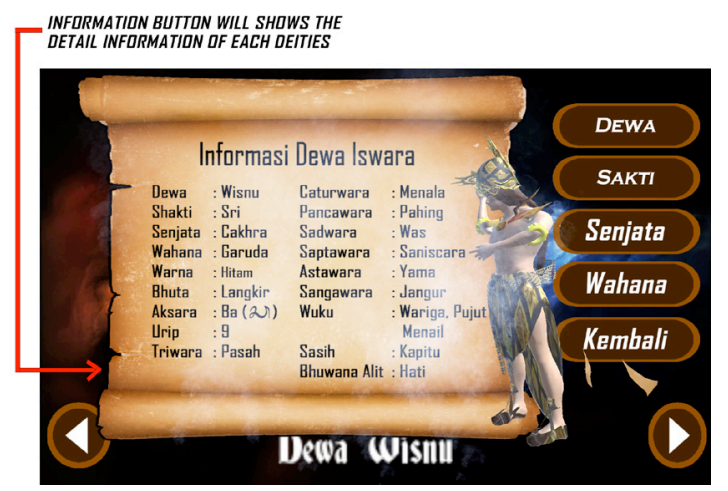

(c)

Fig. 7. Information view

After going through the loading screen, the screen will display Information view (b) that shown in figure (Fig 7). Information view contains eight buttons such as next button, previous button, dewa (deity) button, sakti (deities wife) button, senjata (deities weapon) button, wahana button, kembali (back) button and informasi (information) button. 
The next and previous buttons will display the detailed information menu of the deities sequentially starting from the deities called Vihsnu, Sambhu, Isvara, etc. based on the direction of the wind, but not in the AR view. Sakti button will feature the wife of deity, the senjata button will show the weapon of each deity, the wahana button will show the animal rides of each deity, the kembali button will redirect the user back to AR view. and the last information button will display the deity information in detail and completely as well as be related to the other Hinduism concepts (c) as shown in figure (Fig 7). This information view is made with visualization that has good quality and has a classic concept with shades of Hindu in order to make users more comfortable and interested to use this application.

\section{$5 \quad$ Implementation of System}

AR Dewata Nawa Sanga is developed on the Android operating system using Android 4.1 SDK. This application uses C\# programming language in Monodevelop and building the application using Unity 5.6.1 and creating 3D models of the deities using Blender. Adobe Photoshop is used to design the background. Results from the application created are supported by various smartphone or tablet devices compatible with Android 4.1 (Jelly Bean) or above, and include required sensors such as gyroscopes and compass. System test of AR Dewata Nawa Sanga application uses Android Xiaomi Redmi Note 4 smartphone.

\section{Experiments Design}

These experiments are conducted by assigning tasks to 20 participants to ensure application usability and functionality. The 20 participants are ten women and ten men who are balinese hinduism, and are verified to have an interest in Dewata Nawa Sanga. These experiment participants were asked to complete several tasks on Dewata Nawa Sanga's topic. Almost all the participants seemed very enthusiastic to complete the tasks that have been given. They have promised to do the job honestly to produce a precise, accurate, and useful result for the future.

In total there are five tasks, which are based on the learning objectives of the Nawa Sanga Dewata above (see Section II-A). These tasks are closely related to the content of this application, so it is expected to measure how useful the application is to the participants. In this experiment will also be considered some aspects that are still not perfect to be developed and improved further in the future, so that later this application can be better than before and very useful for the community. The tasks are shown in Table I. After all the tasks are completed, the participants are, then, given additional questions to find the application function of AR Dewata Nawa Sanga according to the task they get. All of these questions are listed in Table II. The purpose of the five tasks is to evaluate the function of the application that is still in this research stage. The main purpose of all these tasks is to evaluate the usefulness of each function of this application. For example, task 1 is to evaluate the gyroscope function in the 
smartphone. Participants can know the direction of the wind in a foreign location with the application when task 1 is successfully done.

After successfully completing the five tasks as well as some questions that have relevance to the usefulness of the application in this research, the participants are given six additional questions and a free response item about their overall function and satisfaction. All of these questions are listed in Table III. All surveys use a fivepoint scale, responses from participants are shown with a score of 5 (strongly agree) to 1 (strongly disagree). The average value of each item of the questionnaire assesses the usefulness of the application, the usefulness of the application, as well as the user satisfaction of this application.

\section{Experiments Result}

\subsection{Application Usefulness}

All survey results related to the utility of the proposed application during the task stage are shown in Table IV. The total of the Q-1 item questionnaire average is $88.4 \%$ that implies sensor compass and gyroscope in the application of augmented reality is very useful to visualize the deities in the nine wind direction in realtime.

Table 1. Experiment Tasks List

\begin{tabular}{|c|c|}
\hline No Items. & Contents \\
\hline $\begin{array}{l}\text { Task1 : } \\
\text { Guess the } \\
\text { direction }\end{array}$ & $\begin{array}{l}\text { First, the participants are asked to show the direction of the winds at night as possible as } \\
\text { in the place that has never been visited. So participants really do not know the directions } \\
\text { of the surrounding winds. Furthermore, they use the AR Dewata Nawa Sanga application } \\
\text { to show wind direction information. }\end{array}$ \\
\hline $\begin{array}{l}\text { Task2: } \\
\text { Mention deities } \\
\text { Position }\end{array}$ & $\begin{array}{l}\text { First, the participants are asked to mention the location of the nine deities in each direc- } \\
\text { tion of the wind, to confirm, participants are asked to see the deities in the application. }\end{array}$ \\
\hline $\begin{array}{l}\text { Task3: } \\
\text { Mention the } \\
\text { warna (color) } \\
\text { of deities }\end{array}$ & $\begin{array}{l}\text { First, the participants who are mostly Hindus after knowing the nine deities are asked to } \\
\text { mention the colors of each deity. The colors are used to be symbolic to offer offerings. } \\
\text { The offerings are rice colored according to the deities. These offerings are usually called } \\
\text { Segehan Panca Warna (Five color offerings). So, some participants may know the colors } \\
\text { of these offerings, but they do not know the meaning of why the color should be in that } \\
\text { position. }\end{array}$ \\
\hline $\begin{array}{l}\text { Task4: } \\
\text { Mention the } \\
\text { wifes of deities }\end{array}$ & $\begin{array}{l}\text { First, participants who already know the names of the deities in the nine wind directions } \\
\text { are asked to answer the sakti (wife) of each deity. Knowledge of the deities is usually not } \\
\text { everyone known because the curriculum in Hinduism during elementary school is not too } \\
\text { complete. After the participants answer, to confirm it then the participants are asked to } \\
\text { find the deities' information from the page of each deity. }\end{array}$ \\
\hline $\begin{array}{l}\text { Task5 : } \\
\text { Mention the } \\
\text { position of } \\
\text { Dewata Nawa } \\
\text { Sanga in the } \\
\text { human body }\end{array}$ & $\begin{array}{l}\text { First, the participants know Hindu has two elements namely macrocosm or called Bhu- } \\
\text { wana Agung and microcosms as Bhuwana Alit. The macrocosm is the universe, mean- } \\
\text { while, the microcosm is the human body. In Dewata Nawa Sanga, the concept is also } \\
\text { implemented. After knowing the contents of information from the macrocosm in the place } \\
\text { of each deity in the universe, now participants are asked to answer the position of Dewata } \\
\text { Nawa Sanga in microcosm or parts of the human body. Then, the answer from the partici- } \\
\text { pants must be confirmed on the application of AR Dewata Nawa Sanga in the Infor- } \\
\text { mation section. }\end{array}$ \\
\hline
\end{tabular}


Table 2. Usefulness Questionnaire

\begin{tabular}{|c|l|}
\hline No Items. & \multicolumn{1}{|c|}{ Contents } \\
\hline Q-1 & $\begin{array}{l}\text { Sensor Compass and Gyroscope in the application of augmented reality is very useful to } \\
\text { visualize the deities in the nine winds in realtime. }\end{array}$ \\
\hline Q-2 & $\begin{array}{l}\text { Placement visualization of 3D Deities is very useful for users to know how the visualization } \\
\text { of Dewata Nawa Sanga in virtual form. }\end{array}$ \\
\hline Q-3 & $\begin{array}{l}\text { The warna (color) information of the Deities in each wind direction is useful for educating the } \\
\text { user about the symbolic colors of the concern in the daily implementation of Hindus for } \\
\text { offerings to the Deities. The color reference of the offering to the deity from Dewata Nawa } \\
\text { Sanga. }\end{array}$ \\
\hline Q-4 & $\begin{array}{l}\text { 3D feature of sakti (wife) of each Deitie is useful to educate users of sakti's information from } \\
\text { the deities that are visualized in 3D. }\end{array}$ \\
\hline Q-5 & $\begin{array}{l}\text { Features Information in this application is useful to explain that the human body also has a } \\
\text { connection with the universe. Dewata Nawa Sanga not only exists in the universe, but also in } \\
\text { the human body. This feature explains the complete information about Dewata Nawa Sanga in } \\
\text { the human body. }\end{array}$ \\
\hline
\end{tabular}

Table 3. Usability and Satisfaction Questionnaire

\begin{tabular}{|c|l|}
\hline No Items. & \multicolumn{1}{|c|}{ Contents } \\
\hline Q-6 & The application is quiet simple to use. \\
\hline Q-7 & This application user interface is good and user-friendly. \\
\hline Q-8 & $\begin{array}{l}\text { The transition loading time from AR view to Information view is very short while using the } \\
\text { application. }\end{array}$ \\
\hline Q-9 & The application to learn about Dewata Nawa Sanga is interesting to use. \\
\hline Q-10 & $\begin{array}{l}\text { The application could educate me in increasing my motivation on Hinduism, definitely about } \\
\text { Dewata Nawa Sanga. }\end{array}$ \\
\hline Q-11 & In the future I will use the same kind of application for Hinduism. \\
\hline
\end{tabular}

Participants state that the position of Dewata Nawa Sanga in AR view can help users to know the position of the wind direction quickly and accurately. During task 1, when the participants are in an unfamiliar location, the AR mode which visualizes the ninth position of the wind direction makes the participants helpful in determining the appropriate directions of the wind. Therefore, for task 2 most participants can show the position of deities in the nine directions because they already know the wind direction with this application (Q-2). The questionnaire items (Q-1 and Q-2) about the usage of AR View has an average of approximately is $89 \%$, which implies that AR View helps students learn more about Dewata Nawa Sanga's postings, and provides a real-world visual learning experience. The average of Q-3 is approximately $89 \%$; it explains that the participants strongly agree that the color information of the deity in each wind direction is useful for educating the user all about the symbolic colors of the concerned in the daily implementation of Balinese Hindus offerings to the deities. Most of participants finally find out the philosophy of the color reference of the offering to the deities from Dewata Nawa Sanga Concept.

A similar experience is also found when answering task 4, which could be answered by only three participants. They can answer task 4 because they have explored knowledge about the wifes of the deities from the internet and stories from their par- 
ents. The Q-4 result has approximately percentage of $87 \%$, in addition to the participants who can answer this task said they agree that this application is very useful for them to know information about the wife of the deities. Furthermore, there are four participants who successfully completed task 5, and they feel there is information about events that are interconnected with the details of each deity in the microcosm. For your information, Hinduism has two elements namely macrocosm or called Bhuwana Agung and microcosm called Bhuwana Alit. Macrocosm in Hinduism is defined as the universe whereas the microcosm is defined as the human body. After knowing the contents of information from the macrocosm in the place of each deity in the universe, the participants finally know the position of Dewata Nawa Sanga in microcosm parts of the human body as seen from the Q-5 result of $87 \%$.

From the analysis and experiments that have been obtained, it can be concluded that AR Dewata Nawa Sanga is very useful and helpful for learners in exploring the Dewata Nawa Sanga position in a real-world environment. This application is also very helpful users to learn about the basic concept of Hinduism that is Dewata Nawa Sanga. Dewata Nawa Sanga has many linkages with other Hindu religious concepts, therefore, users feel very helpful with this application.

Table 4. Result of Usefulness Questionnaire

\begin{tabular}{|c|c|c|c|c|c|c|}
\hline No Items. & $\mathbf{1}$ & $\mathbf{2}$ & $\mathbf{3}$ & $\mathbf{4}$ & $\mathbf{5}$ & Means \\
\hline Q-1 & 0 & 0 & 0 & 10 & 10 & 4.5 \\
\hline Q-2 & 0 & 0 & 4 & 3 & 13 & 4.45 \\
\hline Q-3 & 0 & 0 & 3 & 8 & 9 & 4.45 \\
\hline Q-4 & 0 & 0 & 3 & 7 & 10 & 4.35 \\
\hline Q-5 & 0 & 0 & 4 & 5 & 11 & 4.35 \\
\hline
\end{tabular}

Table 5. Results of Usability and Satisfaction Questionnaire

\begin{tabular}{|c|c|c|c|c|c|c|}
\hline No Items. & $\mathbf{1}$ & $\mathbf{2}$ & $\mathbf{3}$ & $\mathbf{4}$ & $\mathbf{5}$ & Means \\
\hline Q-6 & 0 & 0 & 3 & 2 & 15 & 4.6 \\
\hline Q-7 & 0 & 0 & 4 & 3 & 13 & 4.45 \\
\hline Q-8 & 0 & 1 & 3 & 9 & 7 & 4 \\
\hline Q-9 & 0 & 0 & 3 & 7 & 10 & 4.35 \\
\hline Q-10 & 0 & 0 & 7 & 6 & 7 & 4 \\
\hline Q-11 & 0 & 2 & 4 & 5 & 9 & 4.05 \\
\hline
\end{tabular}

\subsection{System Usability}

Looking from interface design aspect of this application, Most of users agree that the application is easy to use, with an average percentage is $92 \%$ for Q-6, that shown in the Table V. The users can use the application and observe the visualization of Dewata Nawa Sanga. The Q-7 shows the interface is easy to use and very clear with an average percentage is $89 \%$. However, on several occasions, users reported that data in the AR view cannot display complete information, as the user has to press the information button to view the deity information in detail. Furthermore, the average of 
Q-8 is $80 \%$ that indicate the loading time from AR view to Information View is short. There is a problem in the Universe View that shows the area of Dewata Nawa Sanga is quite narrow. While interviewing with the users, they say that the text proportions is very fitting and is judged to have a classical impression with a combination of backgrounds in the lontar form.

\subsection{System Satisfaction}

However, the participants seem very interested in operating this application in order to study Dewata Nawa Sanga, the Q-9 with an average grade value percentage is $87 \%$. Most of the participants say that they initially have no big intention in studying Dewata Nawa Sanga. However, after using this application, they have intention and motivation to learn more about Dewata Nawa Sanga as shown in the average value of Q-10 is $80 \%$. Furthermore, the participants would like that they prefer to use the same Augmented Reality learning application to learn other Hindu religious concepts which is proven the Q-11 value by the average of $81 \%$. They express satisfaction with the implementation of AR Dewata Nawa Sanga and strongly believe that applications with such models can increase their interest and curiosity towards the concept of Hinduism.

In accordance with the contents of the questionnaire, we also ask participants to express their opinion about the application submitted in an honest and realistic way. Four participants said that it would be better if this application inserted the linkage of Dewata Nawa Sanga with other Hinduism concepts; therefore, application users would be more interested to deepen in learning the concept of Hinduism.

\section{Conclusion}

Based on the explanation, we can define the utilization of Augmented Reality technology and 3D content to study Hinduism, especially Dewata Nawa Sanga easily. This application has AR View that is used to see the nine wind directions using gyroscope sensors and compass sensor on the smartphone to show the deity. Furthermore, there is a universe view that is used to understand the position of the nine deities of Hinduism in every direction of the wind in the virtual form and real world background. The gyroscope sensor has an important role in view AR View scene. It is because AR Camera will only work if the camera from the smartphone has a gyroscope sensor. During the development, the AR View has a problem because it contains very many objects and makes the application run slowly, however, this problem is solved by separating the AR View and Information View. This paper also assesses the usefulness of the application, the functionality of the application, as well as the influence of the AR Dewata Nawa Sanga application that can motivate its users. All of these ratings are submitted through task-based experiments. The results of these experiments show that each application function is very useful and has many uses. The AR Dewata Nawa Sanga application is used for learners to increase participants' knowledge in learning objectives of the Hinduism concept. The result of usefulness 
questionnaire of this application percentage value average is $88.4 \%$. It can be concluded that AR Dewata Nawa Sanga is very useful and helpful for learners in exploring the Dewata Nawa Sanga position in a real-world environment. The result of usability and satisfaction questionnaire of this application percentage value average is $84.8 \%$. It shows that the application is very useful for the participants to learn Dewata Nawa Sanga and very satisfied to use. We have plans to improve the design of the application interface design to ensure that even application users with limited knowledge and disability can use it. Furthermore, we will add some additional features such as the ability to display the relevance of Dewata Nawa Sanga with other Hinduism concepts.

\section{Acknowledgment}

The application of AR Dewata Nawa Sanga that has been developed within a few months through a study is part of a project that has a title Markerless Augmented Reality Utilizing Gyroscope to Demonstrate the Position of Dewata Nawa Sanga. This project is supported by Information Technology Department, Faculty of Engineering Udayana University in Indonesia. In addition, we would like to thank Mr. AA.Kt.Agung Cahyawan Wiranatha, Mr. Putu Wira Buana and Mrs. Ni Made Ika Marini Mandenni in Udayana University for their patience in guiding and providing support.

\section{References}

[1] R. T. Azuma, "A Survey of Augmented Reality" Presence: Teleoperators and Virtual Environments," Mitpress, vol. 6, no. 4, pp. 355-385, 1997.

[2] I. M. Endra Wiartika, N. Padma, I. G. M. Darmawiguna, and M. W. Antara Kesiman, "Pengembangan Aplikasi Augmented Reality Book Sistem Rumah Tradisional Bali berdasarkan Asta Kosala-kosali," Janapati, vol. 2, no. 3, pp. 234-242, 2013.

[3] I. K. Yostab Mariyantoni, N. Padma, I. G. M. Darmawiguna, and M. W. Antara Kesiman, "Augmented Reality Book Pengenalan Perangkat Gamelan Bali," Janapati, vol. 3, no. 1, pp. 21-28, 2014.

[4] A. Ferliyanto Waruwu, I. P. Agung Bayupati, and I. K. G. Darma Putra, "Augmented Reality Mobile Application of Balinese Hindu Temples: DewataAR," I. J. Comput. Netw. Inf. Secur., vol. 2, pp. 59-66, 2015.

[5] M. Lester, Professionel Augmented Reality Browsers for Smartphones. United Kingdom: Wiley Publishing, 2011.

[6] Faleniko, "Aplikasi Andorid Augmented Reality Menggunakan Sensor Gyroscope," 2014. [Online]. Available: http://faleniko.com. [Accessed: 03-Jan-2017].

[7] W. Yendra, Kanda Empat Dewa (Manusia Setengah Dewa Sakti Manderaguna). Surabaya: Paramita, 2010.

[8] L. Villarejo, F. González, O. Miralbell, and G. J.M, "Introducing Augmented Reality in Cultural Heritage Studies," eLC, vol. 8, pp. 6-14, 2014. 
Paper-Markerless Augmented Reality Utilizing Gyroscope to Demonstrate the Position of Dewata Nawa...

[9] E. Woods et al., "Augmenting the Science Centre and Museum Experience," in 2nd International conference on Computer Graphics and Interactive Techniques in Australia and Southeast Asia, 2004, pp. 230-236. https://doi.org/10.1145/988834.988873

[10] I. K. T. Adi Stanaya, M. Naseer, and P. N. Crisnapati, "Augmented Reality Book and Stick Application about Pandawa Puppet Shadow Details," JOSINFO, vol. 1, no. 1, 2015.

[11] A. Foni, G. Papagiannakis, and N. Magnenat-Thalmann, "Virtual Hagia Sophia: Restitution, Visualization and Virtual Life Simulation," in UNESCO World Heritage Congress Proceedings, 2002.

\section{Authors}

I Wayan Andis Indrawan is an Undergraduated student of Information Technology Engineering degree in Udayana University, Indonesia.

I Putu Agung Bayupati received the Bachelor of Engineering degree in Electrical Engineering from Udayana University, and Master of Engineering degree in Information Technology from Bandung Institute of Technology and Ph.D degree in Electrical Engineering and Computer Science from Kanazawa University in 2001, 2006 and 2012 respectively. He joined to Udayana University in 2003 as a lecturer. His research interest are in intelegent signal processing, computer vision and image processing.

Desy Purnami Singgih Putri received the Bachelor of Science and Master of Mathematics and Natural Science from Gadjah Mada University. She joined to Udayana University in 2015 as a lecturer. Her research interest are in information technology and applied mathematics.

Article submitted 03 August 2017. Published as resubmitted by the authors 15 October 2017. 